\title{
New Report of Tomato Big Bud Phytoplasma Disease in Dharwad, Karnataka
}

\author{
K. Priyank $\mathbf{a}^{1^{*}}$ and M. S. Patil ${ }^{2}$ \\ Department of Plant Pathology, University of Agricultural Sciences, \\ Dharwad, Karnataka, India \\ *Corresponding author
}

\section{A B S T R A C T}

\begin{tabular}{|l|}
\hline Ke y w ord s \\
Tomato Big Bud \\
Phytoplasma \\
Disease
\end{tabular}

During March 2019 in some of the tomato growing fields of Dharwad it was noticed that tomato plants exhibited malformed flower buds and witches broom symptoms at low incidence level and it was predicted to be big bud phytoplasma infection, therefore, infected and healthy samples were collected for confirmation. Total nucleic acid was extracted by following the CTAB method. Nested PCR was followed using two universal phytoplasma P1/P7 primer set and R16F2n/R16R2n primer set and for which amplification was noticed at $1.8 \mathrm{~kb}$ and $1.2 \mathrm{~kb}$ respectively. The $\mathrm{P} 1 / \mathrm{P} 7 \mathrm{PCR}$ product was further sequenced and BLAST analysis was performed for the sample sequence and it showed that nearly 93 per cent sequence similarity to other phytoplasma sequences in the NCBI database. Thus the present study through molecular analysis confirms the presence of phytoplasma infecting tomato in and around Dharwad.

\section{Introduction}

Tomato big bud disease is caused by phytoplasma and reported to be present across the World (Shaw and Kirkpatrick, 1993; Dale and Smith, 1975; Del Serrone et al., 2001; Anfoka et al., 2003; Ciccarone, 1951; Zimmermann-Gries and Klein, 1978; Vibio et al., 1996). Big bud infection in tomato shows some of the phenotypic abnormalities such as stunted growth, purpling of stem and leaves, enlargement and elongation of stem parts and, enlarged pedicels, malformed buds and sepals with virescent petals and leading to premature flowering (Shaw and Kirkpatrick, 1993; Ghandi et al., 2003; Madhupriya et al., 2018;
Anfoka et al., 2003; Davoodi et al., 2019). The phytoplasma is reported to be transmitted by leaf hopper (Shaw and Kirkpatrick, 1993) and also by psyllids (Hogenhout et al., 2008).

The phytoplasma is a bacteria-like-organism which are devoid of cell wall that multiply inside susceptible host as well as in the vector (Li et al., 2010) and thus leading to reduction in quality of most of the economically important crops. The organism is found to be distributed unevenly in the phloem tissue of the plant host in low titer. Hence detection of this organism should be based on methods that are highly sensitive like the molecular PCR technique. PCR techniques that targets 
the $16 \mathrm{~S}$ rDNA happens to be a promising method to detect this organism (Bertaccini and Duduk, 2009; Rao et al., 2011). Therefore, in the present investigation big bud symptoms on tomato suspected to be infected by phytoplasma was carried to detect and identify the cause using molecular techniques.

\section{Materials and Methods}

\section{Total nucleic acid extraction from infected and healthy sample}

Big bud symptoms showing and also nonsymptomatic healthy tomato samples (Fig. 1) were collected from a field at Dharwadto extract the total nucleic acid. The samples were washed with sterile water to ward off the dust particles and dried on a blotting paper. Later, the samples were crushed in a sterilized pestle and mortar separately using liquid nitrogen. About 100 micro-gram $(\mu \mathrm{g})$ of fine powder was collected into sterilized microcentrifuge tubes. 750 micro-litre $(\mu 1)$ of preheated CTAB extraction buffer $(100 \mathrm{mM}$ Tris $\mathrm{HCl}, 20 \mathrm{mM}$ EDTA, $1.4 \mathrm{M} \mathrm{NaCl}$ and $4 \%$ CTAB) was added and gently vortexed to mix the buffer and fine powder well. To the tubes, $1 \mu \mathrm{l}$ of beta mercapto-ethanol was added and gently mixed by inverting the tubes and incubated at $65^{\circ} \mathrm{C}$ for 20 minutes with frequent mixing of tubes by gentle inversion. Later, chloroform: iso-amyl alcohol (24:1) was added, mixed well and centrifuged at 10000 RPM for 10 minutes. Supernatant was collected and transferred into fresh tubes followed by adding an equal volume of phenol: chloroform:iso- amyl alcohol (25: 24: 1). The tubes were gently mixed and centrifuged at 10000 RPM for 10 minutes, the supernatant was collected and dispensed into fresh tubes. To this, equal volume of chilled iso-propanol was added and incubated overnight at $-20^{\circ} \mathrm{C}$ and then centrifuged at 6000 RPM for 20 minutes to obtain pellets. The supernatant was discarded and ethanol wash was given for the retained pellets and then centrifuged at 6000 RPM for 3 minutes. The upper liquid phase was decanted and pellets were air- dried. $30 \mu \mathrm{l}$ of sterilized TE buffer (10mM EDTA and 1mM Tris, $\mathrm{pH} 8.0$ ) was added to the tubes to dissolve the pellets and was stored at $-20^{\circ} \mathrm{C}$.

\section{Polymerase chain reaction for detection}

About 50ng / $\mu$ lof extracted DNA was used for performing the PCR. Nested PCR was performed using the universal primers for phytoplasmas (Sertkaya et al., 2007; Balol et al., 2016). Initially direct PCR was performed using the first primer set, i.e., P1/P7 (P1 forward- AAGAGTTTGATCCTGGCTC AGGATT and P7 reverse- CGTCCTTCA TCGGCTCTT) with one reaction of initial denaturation at $94^{\circ} \mathrm{C}$ for 5 minutes; 35 cycles of denaturation at $94^{\circ} \mathrm{C}$ for 1 minute, annealing at $55^{\circ} \mathrm{C}$ for 1 minute, extension of $72^{\circ} \mathrm{C}$ for 1 minute; and one cycle of final extension at $72^{\circ} \mathrm{C}$ for 10 minutes. The product was resolved in 1 per cent agarose gel pre-stained with ethidium bromide using gel electrophoresis technique and documented under UV transilluminator. The product was purified and sent for sequencing at Chromous Pvt. Ltd. (Bengaluru).

The product obtained from P1/P7 primer was used as template to perform nested PCR using the nested R16F2/R16R2 primer set (R16F2 forward- ACGACTGCTGCTAAGACTGG; R16R2 reverse - TGACGGGCGGTGT GTACAAACCCCG). The reaction include one cycle of initial denaturation at $94^{\circ} \mathrm{C}$ for 5 minutes; 30 cycles of denaturation at $94^{\circ} \mathrm{C}$ for 1 minute, annealing at $55^{\circ} \mathrm{C}$ for 1 minute, extension of $72^{\circ} \mathrm{C}$ for 1 minute; and one cycle of final extension at $72^{\circ} \mathrm{C}$ for 10 minutes. The PCR product was resolved using 1 per cent agarose gel and documented under UV trans illuminator. 
The sequences of the P1/P7 PCR product were aligned and the aligned sequence was subjected to BLAST analysis for sequence homology search. CLUSTALW and MEGAX bioinformatics tool was used to compare the study sample with other sequences retrieved from NCBI database.

\section{Results and Discussion}

The suspected samples showing symptoms of stunted growth, malformed floral buds, purpling of plant parts as shown in (Fig. 1a-c) were used for total nucleic acid extraction through PCR using phytoplasma universal primers as mentioned above for detection purpose. The P1/P7and R16F2/R16R2 PCR product were resolved through agarose gel electrophoresis technique for which the predetermined amplicon size was obtained at $1.8 \mathrm{~kb}$ and $1.2 \mathrm{~kb}$ respectively. While there was no amplification obtained in the healthy control and no template control (Fig. 2 and 3) indicating positive result pertaining to presence of the phytoplasma infection from the sample collected. The forward and reverse sequence were aligned using the BioEdit tool and the sequence homology search of P1/P7 product nucleotide sequence was performed using the NCBI database through BLAST (www.ncbi.nih.gov/BLAST) which revealed a similarity of $92.89 \%$ with Alfalfa witches broom (Accession ID: EF193360) isolated from alfalfa from Oman (Martini et al., 2007), 92.75\% similarity with Chickpea phyllody (Accession ID:MN453609) isolated from chickpea of Dharwad, India (Balol et al., 2016) and Candidatus Phytoplasma aurantifolia (Accession ID: MK367412) isolated from alfalfa of Iraq (unpublished), 92.73\% Candidatus Phytoplasma aurantifolia (Accession ID: MK965100) isolated from crossandra plant from India (unpublished) and Tomato big bud phytoplasma (Accession ID: KF700081) isolated from infected tomato plants in Coimbatore of India (unpublished).

Fig.1 Big bud symptomatic tomato plants in Dharwad showing virescent symptoms (a), malformed floral buds (b), purpling of plant parts
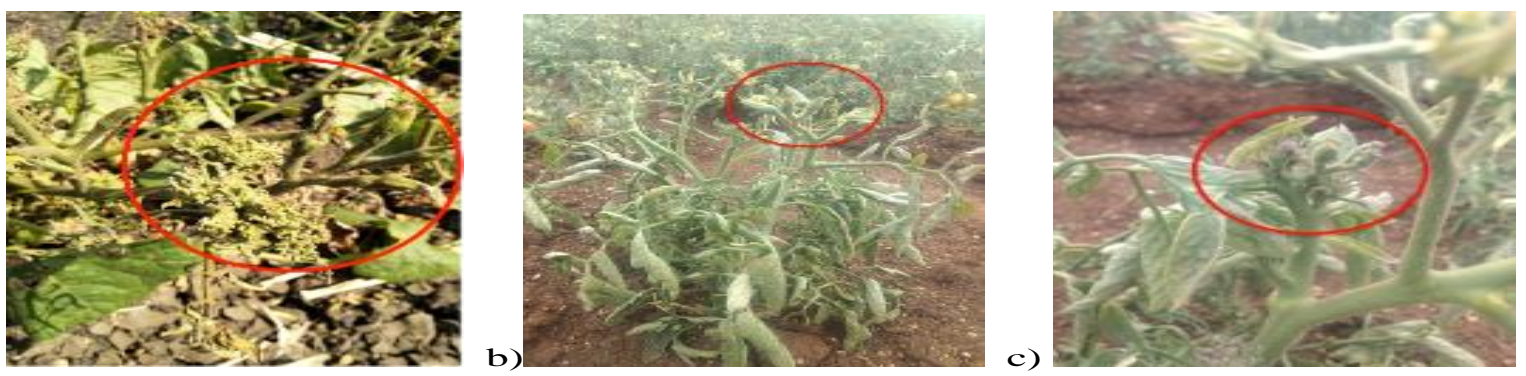

Fig. $2 \mathrm{P} 1 / \mathrm{P} 7$ product amplification at $1.8 \mathrm{~kb}$. Lane 1 and $2=$ test sample with two replication, $\mathrm{L}=$ the marker, $\mathrm{HC}=$ healthy control, $\mathrm{NTC}=$ no template control

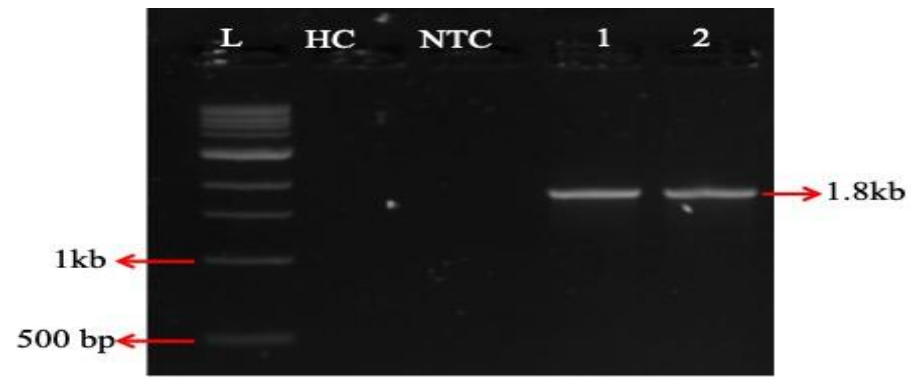


Fig.3 R16F2/R16R2 product amplification at 1.8kb. Lane 1 and $2=$ test sample with two replication, $\mathrm{L}=$ the marker, $\mathrm{HC}=$ healthy control, $\mathrm{NTC}=$ no template control

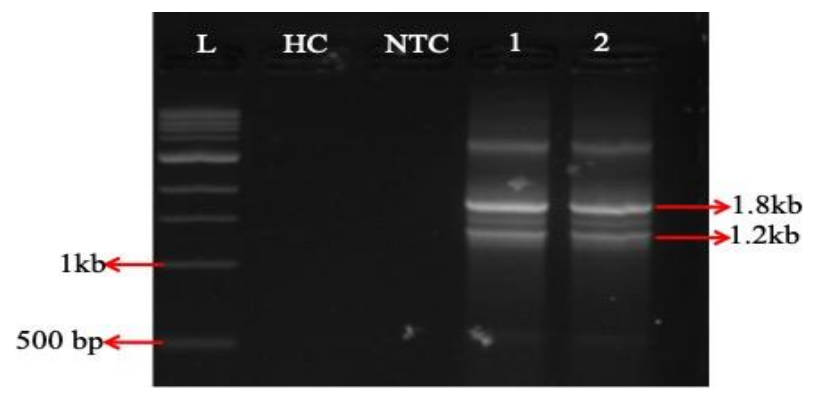

Fig.4 Dendrogram depicting the phylogenetic relationship of MN601398 (GenBank accession ID of study isolate indicated by red triangle) with other phytoplasma sequences retrieved from

NCBI database (indicated by black triangle)

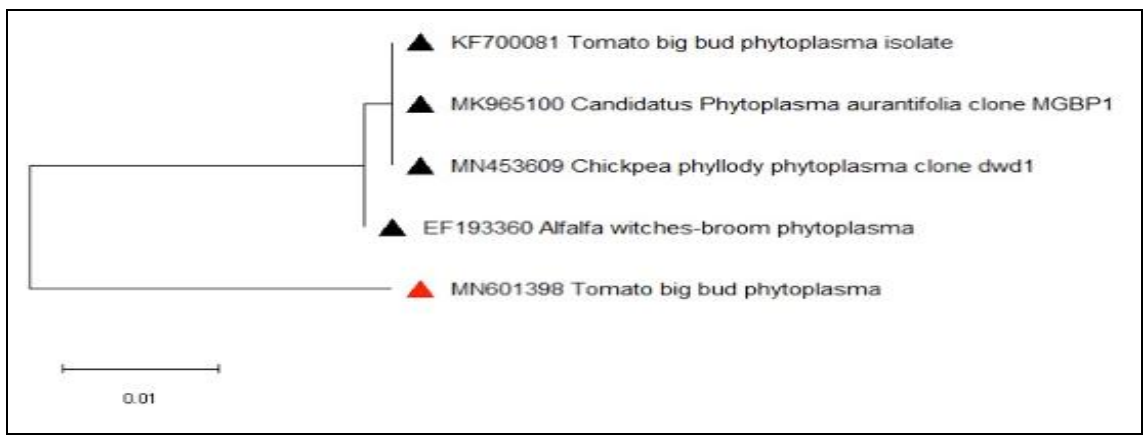

The study sequence was deposited in NCBI GenBank and the accession ID was assigned as MN601398.The phylogenetic relationship of MN601398 with other reference sequence (Fig. 4) shows the divergence into two main branches. One branch includes the MN601398 solely while the other reference sequences used (KF700081, MK965100, MN453609 and EF193360) converged into another branch. KF700081 and MK965100 being more similar with each other were closely related to MN453609. EF193360, MK367412, MK965100 and KF700081 fall under one clade while the one isolated in the present study with GenBank accession ID MN601398 falls into a different clade (Fig. 4), being more similar to Alfalfa witches broom phytoplasma (EF193360). This particular sample was showing similarity to witches broom and tomato big bud reference sequences.
Phytoplasma being wall less bacteria-likeorganism can cause economic yield loss by affecting both quality and quantity in the infecting crop. In tomato different species of phytoplasma are being reported to cause wide range of disease symptoms, among which big bud is one of the phytoplasma diseases being transmitted through leafhopper (Shaw and Kirkpatrick, 1993; Ghandi et al., 2003; Madhupriya et al., 2018; Anfoka et al., 2003; Davoodi et al., 2019). In the present study the symtpoms recorded on tomato were stunted growth, malformed floral buds, purpling of plant parts, virescent petals and, enlarged floral buds. These are the similar symptoms reported earlier by several works as mentioned.

Since phytoplasma resides in the phloem tissue in low concentration, it becomes difficult to detect by traditional techniques. 
Hence, the recent introduction of sensitive molecular techniques solves the problem to decipher the presence of phytoplasma in the infected host even at low concentration. Detection by PCR that utilizes the prokaryotic $16 \mathrm{~S}$ rDNA proves to be a promising approach to detect the organism (Bertaccini andDuduk, 2009; Rao et al., 2011). Therefore, the present study was taken up to detect the phytoplasma infection in tomato through PCR. The direct PCR primer set $\mathrm{P} 1 / \mathrm{P} 7$ and nested primer set R16F2//R16R2 were successfully used to detect and characterize the phytoplasma infecting the sesame crop in Turkey (Sertkaya et al., 2007) and also in chickpea crop in northern Karntaka (Balol et al., 2016).

Hence, the outcome of the investigations indicted that the infected tomato plants with big bud symptoms showed the presence of the phytoplasma and this happens to be first report in this region. Though the tomato big bud disease occurs at low incidence level but later it may emerge in a severe form.

\section{Acknowledgement}

I am grateful Dr. Narayan Moger, Institute of Biotechnology, University of Agricultural Sciences, Dharwad for providing the necessary facilities to carry out the work successfully.

Conflict of interest: No conflicts of interest.

\section{References}

Anfoka, G. H. A., Khalil, A. B. and Fattash, I., 2003, Detection a molecular characterization of phytoplasma associated with big bud disease of tomatoes in Jordan. J. Phytopathol., 151: 223-227.

Balol, G., Channakechava, C. and Patil, M. S., 2016, Molecular characterization of Candidatus

Phytoplasma aurantifolia isolate infecting chickpea (Cicer arietinum) in Dharwad, Karnataka. doi: 10.18805/LR-4156 .

Bertaccini,A. and Duduk, B. 2009. Phytoplasma and phytoplasma diseases: a review of recent research. Phytopathol. Mediterr., 48: 355-378.

Ciccarone, A., 1951, Sintomi di _Virescenzaipertrofica_(Big bud) del pomodoro nei pressi di Roma. Note preliminare. Bollettino Stazione Patologia Vegetale, Serie 3: 193-197.

Dale, J. L. and Smith, L. D., 1975, Mycoplasma like bodies observed in tomato plants with big bud in Arkansas. Plant Disease Reporter, 59: 455-458.

Davoodi, A., Panjekeh, N., Moslemkhani, K. and Taheri, A., 2019, Detection and molecular characterization of tomato big bud disease in Qazvin province. J. Crop Prot.,8 (4):379-388.

DelSerrone, P., Merzachi, C., Bragaloni, M. and Galeffi, P., 2001, Phytoplasma infection of tomato in central Italy. Phytopathol. Mediterr., 40: 137-142.

Ghandi, H., Anfoka, A., Ahmad, B., Khalil, B. and Fattash, I., 2003, Detection and Molecular Characterization of a Phytoplasma Associated with Big Bud Disease of Tomatoes in Jordan. Phytopathology Journal, 151: 223-227.

Hogenhout, S. A., Oshima, K., Ammar, D., Kakizawa, S., Kingdom, H. N. and Namba, S., 2008, Phytoplasmas: bacteria that manipulate plants and insects. Mol. Plant Pathol., 9: 403.423.

Li, Z.N., Song, J. G., Zhang, C. P., Yu, X. Q., $\mathrm{Wu}$, K.K., Wu, W. J., Wu, Y. F. and Xiang, Y., 2010, Berberis phyllody is a phytoplasma-associated disease. Phytoparasitica, 38: 99.102.

Madhupriya, Anitha Kumari, D., Vennila, D. S., Narayana Bhat, M. and Rao, G. P., 2018, Increasing incidence of tomato big bud phytoplasma in Ranga Reddy District of Telangana State, India. 
Indian Phytopathol., 71:207-211.

Rao, G. P., Mall, S., Raj, S. K. and Snehi, S. K., 2011, Phytoplasma diseases affecting various plant species inIndia. Acta Phytopathol. Entomol. Hung, 46: 59.99.

Sertkaya, G., Martini, M., Ermacora, P., Musetti, R. and Osler, R., 2007, Detection and molecular characterization of phytoplasmas infecting sesame and solanaceous crops in Turkey, Bull. Insectol., 60 (2): 141142.

Shaw,M.E. and Kirkpatrick, B. C., 1993, The beet leafhopper transmitted virescence agent causes tomato big bud disease in California. Plant Dis., 77: 290.295.

Vibio, M., Meglioraldi, S., Lee, I. M., Davis, R. E. and Bertaccini, A., 1996,
Genomic variability in $16 \mathrm{~S}$ rI-G phytoplasma infecting tomatoes in Italy and Bulgaria. International Organisation for Mycoplasmology Letters, 4: 260261.

Zimmermann-Gries, S. and Klein, M., 1978, A tomato big bud-like disease of tomatoes in Israel and its association with mycoplasmalike organisms. Plant Disease Reporter, 62: 590-594.

Martini, M., Lee, I.M., Bottner, K.D., Zhao, Y., Botti, S., Bertaccini, A., Harrison, N.A., Carraro, L., Marcone, C., Khan, A. J. and Osler, R., 2007, Ribosomal protein gene-based phylogeny for finer differentiation and classification of phytoplasmas. Int. J. Syst. Evol. Microbiol., 57: 2037-2051.

\section{How to cite this article:}

Priyanka, K. and Patil, M. S. 2020. New Report of Tomato Big Bud Phytoplasma Disease in Dharwad, Karnataka. Int.J.Curr.Microbiol.App.Sci. 9(12): 543-548.

doi: https://doi.org/10.20546/ijcmas.2020.912.065 